\title{
KESIAPAN DAN STRATEGI SMK DALAM MENYELENGGARAKAN PEMBELAJARAN ONLINE: STUDI KASUS DI SMK NEGERI MAGELANG
}

\author{
Aditya Priantara ${ }^{1}$, Nuzulul Alifin Nur ${ }^{2}$, dan Satoto Endar Nayono ${ }^{3}$ \\ 1,2, 3 Pendidikan Teknik Bangunan, FT, UNY \\ Email: Aditya.priantara2016@student.uny.ac.id
}

\begin{abstract}
ABSTRAK
Penelitian ini bertujuan untuk mengetahuitingkat kesiapan sekolah dalam menyelenggarakan pembelajaran on line berdas arkan sumber kesiapan sekolah: menurut guru, sis wa, dan teknisi deng an melihat faktor-faktoryang memengaruhi kesiapan pembelajaran online di SMK Negeri 1 Magelang serta mengetahui strategi pembelajaran on line untuk memperbaiki kesiapan yang didapat. Penelitian ini adalah penelitian deskriptif yang menggunakan metode pengumpulan data dengan cara des kriptif kuantitatif dan deskriptif kualitatif. Teknik pengumpulandata dalam penelitian ini menggunakan kuesioner untuk mendapatkan data kuantitatif dan menggunakan teknik wawancara dan observasi untuk mendapatkan data kualitatif. Sumber data yang menjadi subjek penelitian ini berjumlah 30 guru, 30 siswa program keahlian KGSP, dan 10 orang teknisi untuk mendapatkan data secara kuantitatif, kemudian 1 wakil kepala sekolah bidang kurikulum untuk mendapatkan data kualitatif. Teknik pengambilan data sampel siswa dan guru dari penelitian ini menggunakan teknik simple random sampling kemudian teknik pengambilan data sampel teknisi dan wakil kepala sekolah bidang kurikulumdari penelitian ini menggunakan teknik sampling jenuh. Hasilpenelitian ini dilihat darisegmen kesiapan sekolah menurut guru didapatkan skor 3,2 yang berarti siap, segmen kesiapan sekolah menurut sis wa didapatkan skor 3,01 yang berarti siap, dan segmen kesiapan sekolah menurut teknisi didapatkan skor 3,81 yang berarti sangat siap. Dari hasil wawancara didapatkan hasil bahwa faktor kesiapan guru, kesiapan siswa, faktor infrastruktur, faktormanajemen sekolah, dan faktor budaya sekolah dikategorikan siap dan membutuhkan beberapa strategi sepertimengadakan suatu pelatihan kepada guru maupun sis wa. Di samping itu, dari segi kecenderung an tatap muka dibutuhkan banyak perubahan dan strategi dalam pembelajaran, terutama mengurangi jam tatap muka dan berani untuk menggunakan pembelajaran online. Maka dari itu jika keenam faktor tersebut berada kategori yang siap pembelajaran online akan mendapatkan hasil yang maksimal.
\end{abstract}

Kata kunci: Kesiapan, Strategi, Pembelajaran online

\begin{abstract}
This research aims to determine the level of school readiness in organizingonlinelearning basedonschool readiness: According to teachers, students, and technicians by looking at the factorsaffecting theonlinelearning readiness at SMK Negeri 1 Magelang and knowing online learning strategies to improve thereadinessgained. This research is a descriptive study using methods of data collection with a qualitative, quantitativedescriptive way. The data collection techniques in this study used questionnaires toobtainquantitativedataanduseinterview and observation techniques to obtain qualitative data. The source of the study was 30 teachers, 30 studentsof KGSP membership program, and 10 technicians to get quantitative data, then 1 deputyprincipalofcurriculumto get qualitative data. The techniques of sampling data of students and teachers fromthisstudyused simplerandom sampling techniques and then sample data retrieval techniques and deputy headmasterofthecurriculumfieldof this research using saturated sampling techniques. The results of this study were seen from theschoolreadiness segment by the teacher gained a score of 3.2 which means that the school readiness segmentbystudentsgaineda score of 3.01 which means that it is ready, and the school readiness segment by the technician gainedascoreof 3.81 which means very The results of the interview gained the results that the teacherreadiness, studentreadiness, infrastructure factors, school management factors, and school cultural factors were categorized asreadyand needed some strategies such as conducting training to both teachers and students. Inaddition, intermsofface-toface tendencies required a lot of changes and strategies in learning, especially reducing the hoursofface-to-face and daring to use online learning. Therefore, if the six factors are in a category that is ready foronlineleaming will get maximum results.
\end{abstract}

Keywords: Readiness, Strategy, Online learning 


\section{PENDAHULUAN}

Saat ini perkembangan teknologi dan informasi sangat maju dan modern sehingga membawa dampak terhadap aspek kehidupan manusia. Salah satu aspek yang dipengaruhi oleh perkembangan tersebut adalah pendidikan. Pendidikan yang dahulu menggunakan metode konvensional, sekarang ini harus bisa memanfaatkan teknologi dan informasi yang tersedia.

Teknologi dan informasi sangat dibutuhkan dalam suatu kegiatan pendidikan dan pembelajaran. Teknologi dan informasi yang dibutuhkan dalam kegiatan pembelajaran salah satunya adalah pembelajaran online. Pembelajaran online adalah salah satu aspek penerapan TIK pada sebuah institusi pendidikan. Salah satu pembelajaran online yaitu e-learning.

Menurut Aunnurrahman (2009), elearning terdiri dari dua bagian kata "e" merupakan singkatan dari electronic dan learning artinya pembelajaran. E-learning dapat dikatakan pembelajaran berbasis elektronik yang menggunakan perangkat elektronik. Pembelajaran berbasis elektronik memiliki kelebihan saat melakukan pembelajaran antara dua orang atau lebih karena tidak perlu bertemu dan bertatap muka secara langsung. Di sisi lain e-learning memiliki kelemahan salah satunya yaitu kurangnya interaksi antara siswa dengan guru. Interaksi antara siswa dengan guru tentunya sangat dibutuhkan untuk memantau siswa secara langsung. Kurangnya interaksi dikarenakan e-learning mengutamakan pembelajaran yang bisa dilakukan kapan saja dan dimana saja tanpa harus bertemu dan bertatap muka secara langsung di dalam kelas.

Di sisi lain, e-learning memiliki kelemahan salah satunya yaitu kurangnya interaksi antara siswa dengan guru. Interaksi antara siswa dengan guru tentunya sangat dibutuhkan untuk memantau siswa secara langsung. Kurangnya interaksi dikarenakan e-learning mengutamakan pembelajaran yang bisa dilakukan kapan saja dan dimana saja tanpa harus bertatap muka di dalam kelas. Akan tetapi, interaksi tetap bisa dilakukan dengan cara melakukan pembelajaran e-learning secara bersama di ruangan yang sama.

Pembelajaran online (e-learning) tidak akan berhasil jika siswa dan guru tidak paham cara memakai teknologi tersebut. Maka dari itu, siswa dan guru harus siap dan paham tentang pembelajaran online. Menurut Slameto (2013), proses belajar untuk mencapai tujuan pendidikan mempunyai banyak faktor, salah satunya adalah faktor psikologis yaitu kesiapan. Menurut Depdikbud (1993), kesiapan merupakan keadaan ketika diberikan aksi tertentu. Hal tersebut diartikan bahwa seseorang akan memulai sesuatu kegiatan/aktifitas dapat dikatakan siap jika seseorang bisa melaluinya dengan baik.

Penerapan pembelajaran online membutuhkan kesiapan infrastruktur maupun kesiapan lingkungan wilayah tersebut. Kesiapan ini didapat dengan cara melihat faktor apa saja yang membuat lemah suatu kesiapan untuk menghadapi pembelajaran online. Menurut Karomah, dkk. (2007), kesiapan sekolah dalam menghadapi pembelajaran online dapat diketahui dari sumber: guru, siswa, dan teknisi laboratorium. Menurut Teddy and Swatman (2006), kesiapan pembelajaran online menurut siswa dan guru dikelompokkan menjadi enam faktor meliputi: 1) kesiapan peserta didik,(2) kesiapan guru, 3) infrastruktur, 4) dukungan manajemen, 5) budaya sekolah, dan 6) 
kecenderungan tatap muka. Kemudian menurut Suprayitno (2011), kesiapan pembelajaran online menurut teknisi laboratorium dikelompokkan menjadi tiga faktor meliputi: 1) perencanaan, 2) pengelolaan, dan 3) perawatan.

Terkait dengan kesiapan dan strategi sekolah dalam menghadapi pembelajaran online, penyusun memilih SMK N 1 Magelang sebagai objek penelitian. Terutama guru, teknisi, dan siswa program keahlian KGSP. SMK Negeri 1 Magelang saat ini sedang mengembangkan suatu pembelajaran online yaitu e-learning, akan tetapi dalam penggunaan e-learning masih minim dan hanya beberapa guru saja yang menggunakan, selain itu dari server yang dimiliki SMK Negeri 1 Magelang yaitu moodle hanya dapat digunakan di wilayah sekolah saja. Penggunaan e-learning juga sangat dibutuhkan untuk memperlancar penyampaian materi pembelajaran kepada siswa agar siswa tetap memiliki kompetensi yang sesuai dengan program keahlian KGSP yang ada di SMK Negeri 1 Magelang khususnya dalam kondisi wabah Covid-19 yang terjadi saat ini. Wabah Covid-19 mengakibatkan sistem pembelajaran tatap muka menjadi tidak dapat dilaksanakan, hal ini dikarenakan untuk mengurangi penyebar luasan wabah Covid-19. Maka dari itu diperlukan strategi baru untuk memaksimalkan pembelajaran online dengan menggunakan fasilitas yang disediakan sekolah.

Strategi pembelajaran yang dilakukan SMK Negeri 1 Magelang dirasa masih kurang, pembelajaran yang hanya menggunakan metode ceramah akan membuat siswa bosan. Maka dari itu, SMK Negeri 1 Magelang perlu melakukan strategi baru dengan memperhatikan faktor internal dan faktor eksternal agar pembelajaran menjadi lebih menyenangkan dan mendapatkan hasil yang maksimal. Lingkungan internal yang dimaksud meliputi sikap siswa ketika menggunakan smartphone dan motivasi guru dalam menggunakan pembelajaran online, sedangkan faktor eksternal meliputi sarana dan prasarana yang tersedia di sekolah.

Berdasarkan uraian di atas maka artikel ini bertujuan untuk 1) Mengetahui kesiapan sekolah menurut guru, siswa program keahlian KGSP, teknisi tentang pembelajaran online (e-learning) di SMKN 1 Magelang; dan 2) Mengidentifikasi strategi apa saja yang tepat untuk diterapkan dalam pembelajaran online (e-learning) di SMKN 1 Magelang.

Menurut Effendi dan Zhuang (2005), terminologi e-learning dapat mengacu pada semua kegiatan pelatihan yang menggunakan media elektronik atau teknologi informasi. E-learning memungkinkan siswa untuk belajar sendiri menggunakan komputernya masing-masing tanpa harus secara fisik untuk bertemu dan mengikuti pembelajaran langsung di dalam kelas.

Menurut Andrews (2005), strategi adalah bentuk dari tujuantujuan, kebijakan utama, dan rencana untuk mencapai tujuan yang dipaparkan sedemikian rupa sehingga dapat menerangkan dalam usaha apa organisasi tersebut bergerak.

Teddy \& Swatman (2006), untuk menentukan strategi model pembelajaran online (e-learning) ada enam faktor yang perlu diperhatikan meliputi 1) kesiapan peserta didik; 2) kesiapan guru; 3) factor infrastruktur; 4) faktor dukungan manajemen sekolah; 5) faktor budaya 13 sekolah; dan 6) faktor kecenderungan tatap muka. Berdasarkan enam factor tersebut akan didapatkan suatu strategi baru untuk 


\section{Kesiapan dan Strategi ... (Aditya/ hal. 149-158)}

memperbaiki dan menyelenggarakan pembelajaran online (e-learning).

Supriyono (1985), manfaat strategi terdiri dari 1) Strategi merupakan cara untuk mengantisipasi masalah-masalah dan kesempatan-kesempatan masa depan pada kondisi institusi yang berubah cepat; 2) Strategi dapat memberikan tujuan dan arah institusi di masa depan dengan jelas; 3) Strategi membuat tugas para eksekutif puncak menjadi lebih mudah dan kurang beresiko; dan 4) Strategi membantu praktikpraktik manajemen.

Kesiapan adalah suatu tingkatan untuk menyiapkan diri baik individu maupun organisasi. Kesiapan yang dimaksud adalah siap secara fisik maupun siap secara mental. Kesiapan fisik dan mental ditujukan untuk mempersiapkan kesiapan sekolah dalam menggunakan teknologi pembelajaran online. Kesiapan sekolah dalam pembelajaran onlie mengategorikan kesiapan dalam tiga bentuk sumber menurut guru, siswa, dan teknisi.

Menurut Karomah, dkk. (2007), tingkat kesiapan sekolah dalam menggunakan sistem pembelajaran online dapat diketahui berdasarkan sumber daya manusia yang berada di sekolah: guru, siswa program keahlian kgsp, dan teknisi.

Pengetahuan pentingnya e-learning dalam pembelajaran dapat membantu dan meningkatkan proses belajar mengajar. Semakin banyak guru mengetahui pembelajaran tentang e-learning, maka semakin siap pula sekolah untuk menerapkan e-learning. Pengetahuan elearning seseorang guru dapat diketahui dari guru itu sendiri.

Salah satu pengetahuan guru adalah pengetahuan diri sendiri yaitu mengenal dan memahami secara utuh dirinya sendiri. Guru dapat menilai kesiapan diri sendiri dalam penggunaan e-learning. Kemudian dapat ditambah lagi dengan persepsi dari peserta didik terhadap kesiapan guru dalam penggunaan teknologi dan informasi khususnya pembelajaran e-learning.

Faktor infrastruktur dikatakan siap jika e-learning sudah dapat dilaksanakan. Faktor infrastruktur yang perlu disiapkan meliputi akses wifi, jumlah komputer, biaya, dan alat yang digunakan. Menurut Teddy and Swatman (2006), faktor-faktor ini mencakup lima indikator persepsi menurut guru dan siswa meliputi 1) sekolah memiliki infrastruktur teknologi informasi yang mendukung e-learning; 2) dukungan teknisi terhadap infrastruktur terutama laboratorium computer; 3) sekolah mendukung pembiayaan untuk menerapkan e-learning; 4) akses internet yang tidak terbatas; dan 5) alat-alat yang digunakan tergolong modern.

Menurut Suprihatiningrum (2013), kepala sekolah memiliki tugas pokok dalam hal mencakup kegiatan dan menggali sumber daya yang ada di sekolah untuk pencapaian suatu tujuan tertentu secara efektif dan efisien. Kepala sekolah harus memiliki wawasan yang luas termasuk wawasan dalam pembelajaran elearning. Maka dari itu, guru dan siswa diminta dapat menilai bagaimana kebijakan sekolah, dukungan kepala sekolah, dan rencana pembelajaran sekolah dalam menggunakan e-learning mendatang.

Suryosubroto (2002), unsur personal dalam sekolah adalah kepala sekolah, guru, karyawan, dan peserta didik selanjutnya Suryobroto juga menambahkan bahwa dalam organisasi memiliki prinsip adanya kesatuan arah dari berbagai bagian organisasi. Artinya kepala sekolah, guru, karyawan, dan peserta didik harus melakukan kerjasama agar sistem pembelajaran e-learning dapat tercapai. 
Kerjasama antara guru dan teknisi dapat dilakukan dengan cara saling membantu dan memberi pemahaman tentang pembelajaran e-learning.

Ralmugiz (2015), melakukan penelitian tentang aplikasi model MCKINSEY 7S untuk evaluasi penerapan elearning di SMA Bopkri Yogyakarta. Penelitian ini merupakan penelitian deskriptif dengan menggunakan model kuesioner berdasarkan evaluasi Mckinsey. Kesiapan e-learning di SMA BOPKRI 2 Yogyakarta adalah sangat baik dengan kesiapan persentase elearning sebesar $75,58 \%$. Berdasarkan analisis menggunakan Mckinsey $7 \mathrm{~s}$, terdapat beberapa sub elemen yang harus ditingkatkan antara lain: strategic, plan, size, documentation, IT staff, dan teacher skill. Perbedaan dengan penelitian yang akan dilakukan terdapat pada perhitungan analisis data yang digunakan, serta subjek penelitian dan tempat penelitian.

Yuriani dan Titin (2012), melakukan penelitian tentang Kesiapan mahasiswa pendidikan Teknik Boga dalam pelaksanaan pembelajaran mata kuliah manajemen usaha boga di Program Studi Pendidikan Teknik Boga PTBB FT UNY. Penelitian ini menggunakan pendekatan penelitian deskriptif dan analisis data menggunakan analisis deskriptif kuantitatif dan kualitatif. Hasil penelitian ini mendapatkan hasil kesiapan mahasiswa dalam melakukan persiapan MUB mendapatkan hasil sangat tinggi sebanyak $12,5 \%$ dan hasil kesiapan mahasiswa dalam proses pelaksanaan MUB mendapatkan hasil sangat tinggi sebanyak 16,67\%. Penelitian ini relevan karena menggunakan analisis metode yang sama yaitu analisis kuantitatif dan kualitatif serta meneliti tentang hal kesiapan individu. Perbedaan penelitian yang akan dilakukan terdapat pada subjek penelitian dan tempat penelitian.

\section{METODE}

Penelitian yang berjudul "Kesiapan dan Strategi SMK dalam Menyelenggarakan Pembelajaran Online: Studi Kasus di SMK Negeri 1 Magelang" ini merupakan penelitian deskriptif dengan menggunakan metode penelitian deskriptif kuantitatif dan deskriptif kualitatif. Metode penelitian ini dipilih karena peneliti inin mengetahui tingkat kesiapan sekolah menurut siswa, guru, dam teknisi laboratorium tentang penerapan pembelajaran online serta mengetahui strategi apa yang tepat untuk menyesuaikan pembelajaran online .

Penelitian ini dilaksanakan di SMK Negeri 1 Magelang yang berlokasi di Jalan Cawang No.2 Jurangombo, Kecamatan Magelang Selatan. Magelang Jawa Tengah. Penelitian ini dilaksanakan pada bulan Maret dan berakhir pada bulan April 2020. Pengambilan informan dalam penelitian ini menggunakan teknik penunjukkan dan memilih subjek penelitian berdasarkan bidang studi dan dipandang mempunyai hubungan erat dengan pembelajaran siswa di dalam kelas, yaitu: wakil kepala sekolah bidang kurikulum, teknisi, guru-guru, dan siswa keahlian KGSP.

Teknik pengumpulan data yang digunakan dalam penelitian ini adalah wawancara, kuesioner, dan dokumentasi. Menurut Sugiyono (2012), kuesioner merupakan teknik pengumpulan data yang efisien bila peneliti tahu dengan pasti variabel yang akan diukur dan tahu apa yang diharapkan dari responden.

Instrumen penelitian yang digunakan dalam penelitian ini menggunakan metode kuesioner dan wawancara. Metode 


\section{Kesiapan dan Strategi ... (Aditya/ hal. 149-158)}

kuesioner ini menggunakan empat alternatif jawaban. Uji validitas dan reliabilitas instrumen dalam penelitian ini dilakukan oleh ahli dosen yang bersangkutan dan diukur dengan alat ukur berupa SPSS versi 17.

Berdasarkan analisis yang dilakukan dengan bantuan SPSS versi 17 diperoleh hasil reliabilitas instrumen penelitian.

Tabel 1. Hasil Reliabilitas Instrumen Penelitian

\begin{tabular}{cccc}
\hline No. & Nama & Koef. & Keterangan \\
\hline 1 & $\begin{array}{c}\text { Kesiapan } \\
\text { siswa }\end{array}$ & 0,923 & Reliabel \\
2 & $\begin{array}{c}\text { Kesiapan } \\
\text { guru }\end{array}$ & 0,884 & Reliabel \\
3 & $\begin{array}{c}\text { Kesiapan } \\
\text { teknis }\end{array}$ & 0,985 & Reliabel \\
\hline
\end{tabular}

Teknik analisis data dalam penelitian ini adalah analisis deskriptif, yaitu dengan mendeskripsikan dan memaknai data dari masing-masing aspek yang diteliti. Penilaian tingkat masing-masing indikator dilakukan dengan menghitung nilai mean (rata-rata) dari perolehan skor dalam kuesioner. Nilai yang didapat kemudian dikategorikan dengan perhitungan range score.

Range score $=\underline{\text { nilai tertinggi }- \text { nilai terendah }}$ Jumlah

Range score $=\underline{4-1}=0,75$

4

Tabel 2. Nilai Range Score

\begin{tabular}{ccc}
\hline Nama & Koef. & Keterangan \\
\hline $3,26-4,00$ & Lavel 4 & Sangat Setuju \\
$2,51-3,25$ & Level 3 & Setuju \\
$1,76-2,50$ & Level 2 & Tidak Setuju \\
$1,00-1,75$ & Level 1 & Sangat Tidak \\
& & Setuju \\
\hline
\end{tabular}

Setelah data kuantitatif didapatkan maka ditambahkan data kualitatif dengan cara melalui wawancara kepada responden, yaitu wakil kepala sekolah bidang kurikulum
SMK Negeri 1 Magelang. Wawancara dilakukan dengan cara menggunakan alat bantu smartphone untuk merekam seluruh percakapan dengan responden. Hasil percakapan wawancara ditranskrip dan disimpulkan suatu strategi berdasarkan wawancara terhadap wakil kepala sekolah bidang kurikulum.

\section{HASIL DAN PEMBAHASAN}

Penelitian ini merupakan jenis penelitian deskriptif yang menghasilkan dua data penelitian yaitu data deskriptif kuantitatif berdasarkan sumber kesiapan menurut guru, siswa, dan teknisi. Kemudian data deskriptif kualitatif yang bertujuan untuk menyusun strategi pembelajaran online di SMK Negeri 1 Magelang.

Secara keseluruhan tingkat kesiapan SMK Negeri 1 Magelang menurut guru, siswa, dan teknisi tentang kesiapan pembelajaran online dapat dikategorikan dalam kategori siap. Data berupa hasil yang diperoleh dari responden sebanyak 30 responden siswa, 30 responden guru, dan 10 responden teknisi. Kemudian dianalisis berdasarkan faktor-faktor kesiapan sekolah tentang pembelajaran online. Angket penelitian ini memiliki 19 pernyataan menurut siswa, 18 pernyataan menurut guru, dan 12 pernyataan menurut teknisi dengan alternatif jawaban "Sangat Setuju" dengan skor 4, "Setuju" dengan skor 3, "Kurang Setuju" dengan skor 2, "Tidak Setuju" dengan skor 1 .

Dalam menghitung hasil rata-rata penelitian ini menggunakan software aplikasi Microsoft Excel versi 2013. Dari rata-rata setiap faktor dikelompokkan ke dalam tabel Range Score untuk menentukan kesiapan sekolah dalam menyelenggarakan pembelajaran online. 


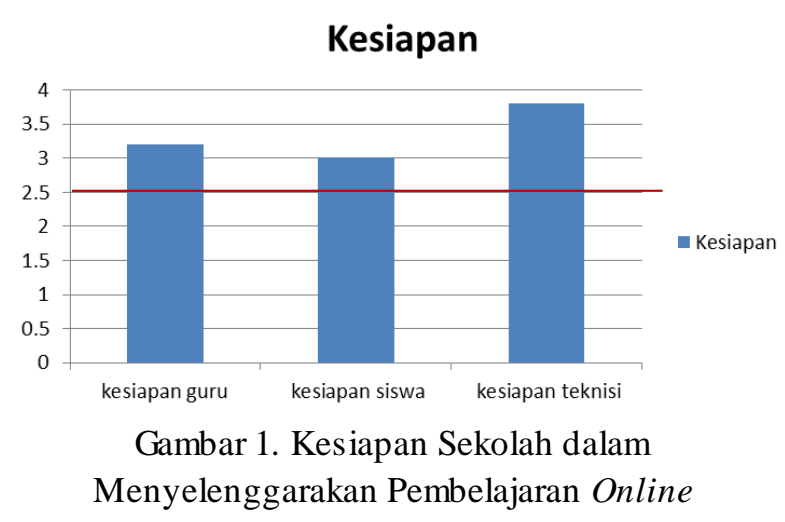

\section{Kesiapan Sekolah menurut Guru}

Berdasarkan kesiapan sekolah menurut guru didapatkan skor rata-rata sebesar 3,2 atau 79,22\%. Hal ini dikategorikan ke dalam perhitungan range score maka didapatkan hasil siap dengan level tiga. Hal ini diartikan penerapan pembelajaran online di SMK Negeri 1 Magelang sudah siap namun membutuhkan sedikit peningkatan. Kemudian dari hasil rata-rata tersebut ditinjau ke enam faktor yang mempengaruhi hasil kesiapan tersebut.

Teddy \& Swatman (2006) menyebutkan ada beberapa faktor yaitu 1) Faktor kesiapan peserta didik memiliki skor rata-rata sebesar 3,31 atau 82,9\%. Berdasarkan persepsi guru, peserta didik siap untuk menerapkan e-learning di sekolah.; 2) Faktor kesiapan guru mendapatkan skor rerata sebesar 3,43 atau $85,83 \%$; 3) Berdasarkan faktor infrastruktur mendapatkan skor rata-rata sebesar 3,25 atau 81,3\% yang artinya siap; 4) Berdasarkan faktor dukungan manajemen mendapatkan skor rata-rata sebesar 3,24 atau $81,1 \%$; 5) Berdasarkan butir indikator dari faktor budaya sekolah didapatkan skor rata-rata 3,53 atau 88,3\%; dan 6) Skor rata-rata yang didapat dari faktor kecenderungan tatap muka sebesar 2,23 atau 55,83\%.

\section{Ke siapan Sekolah me nurut Sis wa}

Berdasarkan kesiapan sekolah menurut siswa didapatkan skor rata-rata sebesar 3,01 atau 76,11\%. Hal ini dikategorikan ke dalam perhitungan range score maka didapatkan hasil siap dengan level tiga. Hal ini diartikan penerapan pembelajaran online di SMK N Magelang sudah siap namun membutuhkan sedikit peningkatan. Kemudian dari hasil rata-rata tersebut ditinjau ke enam faktor yang mempengaruhi hasil kesiapan tersebut.

Teddy \& Swatman (2006), menyebutkan ada beberapa faktor yaitu 1) Faktor kesiapan peserta didik mendapatkan skor rata-rata sebesar 3,21 atau $80,41 \%$; 2) faktor kesiapan guru mendapatkan skor ratarata sebesar 2,92 atau $73,16 \%$; 3) faktor infrastruktur menurut persepsi siswa mendapatkan skor rata-rata sebesar 2,9 atau 72,67\% sehingga dapat dikatakan siap; 4) faktor dukungan manajemen mendapatkan skor rata-rata sebesar 2,95 atau 73,8\%; 5) Faktor budaya sekolah mendapatkan skor ratarata sebesar 3,21 atau 80,4\%; dan 6) faktor kecenderungan tatap muka sebesar 2,2 atau 57,083 dikategorikan tidak siap.

\section{Kesiapan Sekolah menurut Teknisi}

Berdasarkan kesiapan sekolah menurut mendapatkan skor rata-rata sebesar 3,81 atau 95,5\%. Hal ini dikategorikan ke dalam perhitungan range score maka didapatkan hasil sangat siap dengan level empat. Hal ini diartikan penerapan pembelajaran online di SMK N 1 Magelang suda siap. Kemudian dari hasil rata-rata tersebut ditinjau ke tiga faktor yang mempengaruhi hasil kesiapan tersebut.

Suprayitno (2011), ada tiga faktor yaitu 1) faktor perencanaan memperoleh skor rata-rata 3,84 atau $96,25 \%$; 2) faktor pengelolaan memperoleh skor rata-rata sebesar 3,82 atau 96,7\%; dan 3) faktor perawatan memperoleh skor rata-rata sebesar 3,76 atau $93,75 \%$. 
Berdasarkan faktor-faktor yang ditinjau, faktor kecenderungan tatap muka menjadi faktor yang masih lemah dan masih belum siap diterapkan. Dikarenakan SMK N 1 Magelang lebih sering melakukan pembelajaran secara tatap muka sehingga pembelajaran tanpa tatap muka masih jarang dilakukan.

Selain data dari kuesioner dengan skala nilai 1-4 seperti diatas, dalam pengambilan data dengan metode wawancara didapatkan data deskriptif kualitatif, dimana hasil wawancara ini menjadi strategi pembelajaran online di SMK N 1 Magelang untuk kedepannya. Data wawancara diuraikan sebagai berikut: 1) Kesiapan siswa, dari faktor ini dapat dilihat bahwa kesiapan siswa dalam menggunakan internet, komputer, dan pembelajaran online sudah berjalan. Hanya saja perlu ditambah berupa pengenalan dasar-dasar pembelajaran online (e-learning) melalui pelajaran TIK; 2) Kesiapan guru, dari faktor ini dapat dilihat beberapa guru sudah menjalankan proses pembelajaran online. contohnya saja beberapa guru menggunakan aplikasi Microsoft Powerpoint dan mengirimkannya melalui internet. Strategi yang perlu dijalankan dari kesiapan guru ini adalah mengumpulkan semua guru muda dan melakukan pelatihan tentang penggunaan komputer dan internet; 3) Infrastruktur, dari faktor ini sarana dan prasarana yang ada suda cukup untuk mendukung adanya pembelajaran online, seperti contoh pengadaan laboratorium, jaringan internet, dan wifi. Strategi yang perlu ditambahkan dari faktor ini adalah menambah jumlah komputer yang ada. Dikarenakan agar saat melakukan pembelajaran menggunakan komputer siswa tidak perlu menunggu dan bergantian dengan siswa lainnya; 4) Manajemen sekolah, dari faktor ini kepala sekolah dan wakil kepala sekolah sangat memahami dan mendukung adanya pembelajaran online (elearning. Kepala sekolah juga memahami bahwa siswa lebih suka membaca informasi dan materi yang ada melalui alat elektronik seperti handphone dan komputer. Strategi yang akan dilakukan dari faktor ini yaitu mengkombinasikan

pembelajaran konvensional dengan pembelajaran online; 5) Budaya sekolah, dari faktor ini sekolah sudah menerapkan budaya bertegur sapa antara guru dengan siswa maupun sebaliknya. Strategi yang akan dilakukan dari faktor ini mencakup pembelajaran elearning adalah dengan menggunakan manajemen review yang ada di sistem elearning. Hal tersebut akan membuat guruguru saling bekerja sama dalam hal teknologi dan pembelajaran. Karena manajemen review berfungsi untuk mengevaluasi sistem manajemen mutu yang ada sehingga guru akan bekerjasama untuk memperbaiki evaluasi tersebut; dan 6) Pembelajaran tatap muka, dari faktor ini dapat dilihat masih banyaknya guru yang menggunakan pembelajaran dengan metode tatap muka sehingga dibutuhkan strategi baru. Strategi yang dilakukan adalah menggunakan pembelajaran dengan dua metode yaitu secara tatap muka dan online (e-learning). Metode pembelajaran online dan konvensional dilakukan secara berimbang agar para guru dapat memberikan wadah kepada siswa dalam menerapkan pembelajara online.

Dari uraian data wawancara diatas dapat ditarik kesimpulan bahwa faktor kecenderungan tatap muka masih sering dilakukan sehingga pembelajaran online ( $e$ learning) masih jarang dilakukan.

Dari hasil analisis data angket didapatkan dari keenam faktor kesiapan 
pembelajaran online. faktor kecenderungan tatap muka menjadi faktor yang masih lemah dan masih sering dilakukan sehingga pembelajaran online (e-learning) sangat jarang dilakukan.

\section{SIMPULAN}

Berdasarkan data hasil penelitian dan pembahasan yang telah diuraikan maka dapat disimpulkan sebagai berikut yaitu penelitian ini menggunakan instrumen dengan memperhatikan enam faktor kesiapan sekolah dalam menggunakan pembelajaran online menurut guru dan siswa. Kemudian menggunakan tiga faktor kesiapan sekolah dalam menggunakan pembelajaran online menurut teknisi. Serta strategi menurut wakil kepala sekolah bidang kurikulum. Secara keseluruhan SMK N 1 Magelang sudah siap jika diterapkan atau diselenggarakan pembelajaran berbasis online. Hanya saja jika dilihat berdasarkan faktor-faktor yang mempengaruhi kesiapan tersebut. Dari segi analisis menggunakan data angket faktor kecenderungan tatap muka masih sangat rendah dan masih sering digunakan sehingga pembelajaran online di SMK N 1 Magelang masih jarang digunakan. Ditambah lagi pendapat menurut wakil kepala sekolah bidang kurikulum, memang benar guru-guru di SMK N 1 Magelang masih sering menggunakan metode pembelajaran secara konvensional sehingga pembelajaran online masih minim untuk digunakan.

Dengan demikian, setelah mengetahui kesiapan dan strategi SMK N 1 Magelang dalam menerapkan pembelajaran online, diharapkan nantinya SMK N 1 Magelang dapat mengetahui faktor-faktor apa saja yang perlu diperbaiki dan dihilangkan sehingga pembelajaran online di SMK N 1
Magelang dapat terlaksana dan berjalan dengan baik.

\section{DAFTAR RUJUKAN}

Andrews, K. (2005). Konsep Strategi Perusahaan. Jakarta: Erlangga.

Aunnurrahman. (2009). Belajar dan Pembelajaran. Bandung: Alfabeta.

Depdikbud. (1993). Kamus Besar Bahasa Indonesia. Jakarta: Balai Pustaka.

Effendi dan Zhuang. (2005). E-learning, Konsep dan Aplikasi. Yogyakarta: Andi Offset.

Karomah, Marwanti dan Ali. (2007). Implementasi Pembelajaran Elearning Program Adaptif Bagi Guru SMK di Daerah Istimewa Yogyakarta. Laporan Penelitian Lembaga Penelitian UNY.

Ralmugiz, U. (2015). Aplikasi Model MCKINSEY 7S untuk Evaluasi Penerapan ELearning di Sekolah Menengah Atas Bopkri Yogyakarta. Skripsi. Yogyakarta: Universitas Negeri Yogyakarta.

Slameto. (2013). Belajar dan Faktor-Faktor yang Mempengaruhinya. Jakarta: Rineka Cipta.

Sugiyono. (2012). Metode Penelitian Kuantitatif Kualitatif dan R\&D. Bandung: Alfabeta.

Suprayitno. (2011). Panduan Teknis Perawatan Laboratorium Komputer 
\& Multimedia. Jakarta: Kementrian Pendidikan dan Kebudayaan.

Suprihatiningrum, J. (2013). Strategi Pembelajaran. Yogyakarta: Ar-Ruzz Media.

Supriyono. (1985). Manajemen Strategi dan Kebijaksanaan Bisnis. Yogyakarta: BPFC.

Suryosubroto. (2002). Proses Belajar Mengajar Di Sekolah. Jakarta: Rineka Cipta.

Teddy, \& Swatman, P. M. C. (2006). Elearning Readiness of Hong Kong Teachers. The Jurnal of Education Research University of South Australia.

Yuriani, dan Handayani, T. H. W. 2012. Kesiapan Mahasiswa Pendidikan Teknik Boga dalam Pelaksanaan Pembelajaran Mata Kuliah Manajemen Usaha Boga di Program Studi Pendidikan Teknik Boga PTBB FT UNY. Jurnal JPTK (Vol. 21 No. 2): Universitas Negeri Yogyakarta. Dari https://journal.uny.ac.id/index.php/i ptk/article/view/3286 